\title{
Lemons or Cherries? Asymmetric Information in the German Private Long-term Care Insurance Market
}

\author{
Mark J. Browne ${ }^{\mathrm{a}}$ and Tian Zhou-Richter ${ }^{\mathrm{b}}$

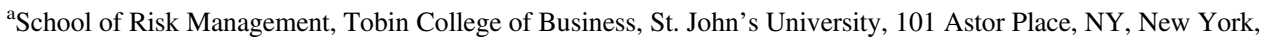 \\ 10003 USA. \\ ${ }^{\mathrm{b}}$ Munich Reinsurance Company, Konigistrasse 107, Munich, 80802 Germany. \\ E-mail: tzhou-richter@munichre.com
}

This study provides evidence of the presence of asymmetric information in the German long-term care (LTC) insurance market. While certain private information-individuals' pessimism level and preference for insurance-contributes to advantageous selection, the major source of adverse selection-individuals' self-assessed high LTC risk-switches the final correlation between insurance and risk to one that is significantly positive. In addition, the study reveals that although individuals' self-assessment of poor health predicts their future care needs very well, such assessments are not necessarily reflected in insurance demand. The results from this study could assist insurers in better understanding and managing LTC risk.

The Geneva Papers (2014) 39, 603-624. doi:10.1057/gpp.2014.25

Keywords: private information; long-term care insurance; adverse selection; advantageous selection

Article submitted 7 February 2013; accepted 23 June 2014; published online October 2014

\section{Introduction}

Information on risk is the basis for underwriting and pricing insurance. Asymmetrically distributed information in favour of the buyer of insurance provides the insured the opportunity to act strategically in the transfer of risk through the marketplace. Whether information known to the buyer of insurance but not the insurer, hereafter referred to as private information, results in adverse selection or advantageous selection is the focus of the current study.

There are two predominant theories as to the effects of asymmetric information on the purchase of insurance. One theory, known as the "lemons principle", concentrates on adverse selection, and suggests that high-risk agents choose to purchase more insurance coverage than do low-risk agents. ${ }^{1}$ A testable prediction of adverse selection theory is that risk occurrence is positively correlated with insurance coverage.

The second theory as to the effects of asymmetric information concentrates on advantageous selection. This theory is also called "cherry picking". ${ }^{2}$ Advantageous selection stresses the role of individuals' risk aversion and argues that more risk-averse agents are both

\footnotetext{
${ }^{1}$ Akerlof (1970), Rothschild and Stiglitz (1976).

2 The term "cherry picking" comes from the observation that cherries selected for the market are usually "the best of the bunch". This definition was first used in Chiappori and Salanié (2000) to describe advantageous selection in insurance markets.
} 
more willing to purchase insurance and more cautious. ${ }^{3}$ In the presence of advantageous selection, insurance coverage and risk occurrence are negatively correlated.

This paper aims to answer empirically two research questions. First, do individuals have private information that is associated with either adverse or advantageous selection? Private information is known to the applicant for insurance but not the insurance company. Second, which selection effect (adverse or advantageous) is more pronounced? That is, conditional on the information known by both parties, is the additional information known by insureds associated with insurance purchasing behaviour consistent with adverse selection theory or with advantageous selection theory? The current paper extends our understanding of the association between private information held by individuals and the purchase of insurance. The study considers multiple types of private information, some of which would reasonably be expected to be associated with adverse selection and others that would be expected to be associated with advantageous selection. We consider both types of information simultaneously in our models. While we hypothesise that both types of information will be associated with insurance consumption, a priori we do not have a hypothesis on which will dominate. Our analysis reveals sources of both adverse and advantageous selection in the German private long-term care (LTC) market. We find that the sources of adverse selection have a dominant impact over those of advantageous selection.

Sample data for this study are drawn from the German Socio-Economic Panel Study (SOEP), a representative longitudinal study of private households in Germany. These data, which include both insureds and non-insureds, track their LTC need over 11 years. The SOEP data report on both those who receive LTC care in a nursing home and those who receive care in a non-institutional setting, typically one's home or that of a family member.

The remainder of the paper is structured as follows. The next section presents the theoretical background of the study. The econometric properties of sources of adverse and advantageous selection are introduced thereafter. The subsequent section describes the data and variable settings applied in this paper. The penultimate section reports the empirical results on the sources of adverse and advantageous selection. The last section concludes and draws implications from the paper's main findings.

\section{Theoretical background}

\section{Adverse and advantageous selection}

A growing body of literature, which we briefly discuss in this section, focuses on the effects that private information may have on insurance markets. In this section, we also review the empirical tests employed in prior research to test for asymmetric information in insurance markets.

Economists have studied how asymmetric information affects the operation of insurance markets. Akerlof ${ }^{4}$ analyses the "lemons principle", also known as adverse selection, in a supply-and-demand model and argues that, in the presence of asymmetric information, better

\footnotetext{
${ }^{3}$ Chiappori and Salanié (2000), de Meza and Webb (2001).

${ }^{4}$ Akerlof (1970).
} 
risks may be driven out of an insurance market by worse risks. Rothschild and Stiglitz ${ }^{5}$ find that high-risk insureds will choose insurance contracts with more comprehensive coverage than low-risk insureds. These two studies predict a positive correlation between insurance coverage and risk occurrence.

A positive correlation between insurance and risk is not found in numerous empirical studies. Chiappori and Salanié ${ }^{6}$ and Saito ${ }^{7}$ analyse automobile insurance markets and find no evidence of a positive correlation between the amount of insurance purchased and the occurrence of an accident. Finkelstein and McGarry ${ }^{8}$ come to a similar conclusion, finding the absence of a positive correlation in the U.S. LTC insurance market. Cawley and Philipson ${ }^{9}$ and McCarthy and Mitchell ${ }^{10}$ even find evidence of a negative correlation and point out that individuals with life insurance have lower mortality risk relative to the general population. ${ }^{11}$

In an attempt to explain this puzzling empirical evidence, several theoretical papers introduce the "cherry picking" or "advantageous selection" effect, which has to do with good risks buying more insurance, and discuss the possibility of multi-dimensional private information. Private information is known to the applicant for insurance but not to the insurance company. Most of these papers stress the role of individuals' risk preference as additional private information and argue that more risk-averse agents are both more willing to purchase insurance and to exert more caution. ${ }^{12,13}$

This study is closely related to two papers: Finkelstein and McGarry ${ }^{8}$ and Fang et al. ${ }^{14}$ Since demand for insurance is conditional on the information known to the insurer, which is reflected in underwriting and pricing decisions, these studies control for the information known by both applicants and insurers in their analyses. Finkelstein and McGarry ${ }^{8}$ examine the relationship between LTC insurance ownership and nursing home entry over five years for U.S. survey respondents born in 1923 or earlier. They find that respondents possess two types of private information-information about their own risk type and information as to their own risk preference. These have offsetting effects on insurance coverage and risk occurrence, and result in insured and uninsured people having a similar probability of entering a nursing home. Fang et al. ${ }^{14}$ find evidence that income, education, longevity expectations, the financial planning horizon and cognitive ability are major sources of advantageous selection. While similar to the preceding research in focus, our study contributes to this body of research by considering selection effects in the German LTC market. We find that sources of adverse selection dominate those of advantageous selection in this market.

${ }^{5}$ Rothschild and Stiglitz (1976).

${ }^{6}$ Chiappori and Salanié (2000).

${ }^{7}$ Saito (2006).

${ }^{8}$ Finkelstein and McGarry (2006).

${ }^{9}$ Cawley and Philipson (1999).

${ }^{10}$ McCarthy and Mitchell (2010).

${ }^{11}$ For a detailed overview of recent empirical work testing for the presence of correlation between risk and insurance in different insurance markets, see Cohen and Siegelman (2010).

12 Hemenway (1990), Chiappori and Salanié (2000), de Meza and Webb (2001), Chiappori et al. (2006).

${ }^{13}$ Contrary to these works, Cohen and Einav (2007) find a positive correlation between risk and risk aversion for the Israeli auto insurance market. However, the authors state that this correlation is sensitive to assumptions and could reverse sign if the claims are not assumed to follow a Poisson process.

${ }^{14}$ Fang et al. (2008). 
606

This study aims to shed light on adverse and advantageous selection in the context of the German private LTC insurance market. By breaking down the asymmetric information into two dimensions - sources of adverse vs advantageous selection-this study explores and compares the impact of these two kinds of selection on the correlation between LTC insurance ownership and actual care need. Our empirical analysis in this study does not test for causality. Consequently, we are able to report associations between variables that are consistent with adverse or advantageous selection; however, we are not able to rule out moral hazard as an alternative explanation.

\section{Testing for asymmetric information}

Theory suggests three testable consequences of adverse selection, as summarised in Chiappori ${ }^{15}$ : (1) the presence of adverse selection restricts market size and amplifies the proportion of high-risk agents among insurance purchasers; (2) high-risk agents purchase more insurance coverage than low-risk agents; and (3) because of the overrepresentation of high-risk agents in the pool purchasing coverage, the unit price in the actual insurance market is higher than it would be in the absence of adverse selection. The empirical test for adverse selection is based on one important conclusion from Rothschild and Stiglitz ${ }^{5}$, who specifically suggest that, under adverse selection in a competitive market, high-risk agents, given a "menu" to choose from, will pick contracts with more comprehensive coverage. This conclusion, as pointed out in Chiappori and Salanié ${ }^{6}$, provides a simple test, that is, insurance coverage should be positively correlated with ex post risk occurrence in the presence of adverse selection.

The methodologies employed to identify the correlation between risk and insurance can be grouped into the following categories. The first approach is the bivariate probit model, that is, an independence test of two probit models (or), which was introduced in Chiappori and Salanié. ${ }^{6}$ This entails estimating a pair of probit models, one with insurance coverage as the dependent variable and the other with accident occurrence as the dependent variable. Information observable to the insurance company, such as age and gender, is regressed against the dependent variable in each equation. By testing the independence of the residuals from both probit estimations, one can judge whether insurance coverage and accident occurrence are correlated. If the two model residuals are assumed to be dependent, this approach becomes the test of a bivariate probit model. This approach is called the positive correlation property test.

The second methodology is the univariate probit/logit model approach, which either regresses insurance ownership on ex post risk occurrence or regresses ex post risk occurrence on insurance ownership. Browne ${ }^{16}$ estimates a logit model of LTC insurance coverage on the predicted losses for seven successive years to analyse whether those with higher predicted losses are more likely to retain coverage following a rate increase. Fang et al. ${ }^{14}$ regress Medigap coverage on medical expenditures and potential sources of advantageous selection, controlling for health measures and demographics. Variables that increase the coefficient of medical expenditure are regarded as sources of advantageous selection. Finkelstein and McGarry ${ }^{8}$ estimate a probit model of nursing home use as a function of insurance coverage.

\footnotetext{
${ }^{15}$ Chiappori (2000).

${ }^{16}$ Browne (2006).
} 
This study employs the bivariate probit model because it better illustrates both the correlation of private information with insurance coverage and its correlation with ex post risk occurrence. The bivariate probit model, compared to the two-probit model that assumes independent residuals, also has the advantage that the estimation is efficient in case of dependence between insurance and risk. ${ }^{6,17}$

\section{Econometric properties of sources of adverse and advantageous selection}

In this section, we present our econometric models for testing for adverse selection and advantageous selection. In this paper, LTC insurance ownership (INS) and ex post care need $(C A R E)$ are specified as binary outcomes that depend on individuals' observables and private information. On the basis of the reasoning set out above, we apply a bivariate probit model to examine the correlation between insurance and risk. This approach assumes that the residuals of the two probit models are joint normal distributed with means zero, variances one, and correlation $\rho$. We estimate a bivariate probit model as follows:

$$
\begin{gathered}
I N S=\mathbf{1}(\mathbf{D} \beta+\varepsilon>0) \\
C A R E=\mathbf{1}(\mathbf{D} \delta+\eta>0) \\
\text { with }\left(\begin{array}{l}
\varepsilon \\
\eta
\end{array}\right) \mid(\mathbf{D}) \sim N\left(\left(\begin{array}{l}
0 \\
0
\end{array}\right),\left(\begin{array}{ll}
1 & \rho \\
\rho & 1
\end{array}\right)\right) .
\end{gathered}
$$

$\mathbf{1}(\cdot)$ denotes an indicator function. Vector $\mathbf{D}$ includes risk classification criteria used by insurance companies to discriminate between insurance applicants and set risk-adequate insurance prices. We incrementally add sources of adverse selection and advantageous selection to vector $\mathbf{D}$ to investigate how the different types of private information affect the correlation between insurance and risk. $\beta$ and $\delta$ are coefficients of explanatory variables in vector $\mathbf{D}$.

This bivariate probit model assumes that the residuals $\varepsilon$ and $\eta$ are standard normal distributed and have a correlation coefficient $\rho$. On the basis of the sample data for this study, we can estimate the correlation coefficient and obtain its significance level, which reveals whether and how LTC insurance ownership and actual care need are correlated.

To test $\rho\left(\varepsilon_{i}, \eta_{i}\right)=0$, it is necessary to calculate the residuals after the bivariate probit Models (1) and (2) are estimated. The residual $\hat{\varepsilon}_{i}$ of individual $i$, for, say, Model (1), is given as follows:

$$
\hat{\varepsilon}_{i}=E\left(\varepsilon_{i} \mid I N S_{i}\right)=\underbrace{\frac{\varphi\left(\mathbf{D}_{i} \hat{\beta}\right)}{\Phi\left(\mathbf{D}_{i} \hat{\beta}\right)}}_{\text {factorA }} I N S_{i}-\left(1-I N S_{i}\right) \underbrace{\frac{\varphi\left(\mathbf{D}_{i} \hat{\beta}\right)}{\Phi\left(-\mathbf{D}_{i} \hat{\beta}\right)}}_{\text {factorB }},
$$

where $\varphi$ and $\Phi$ indicate the density and the cumulative distribution of a standard normal distribution.

${ }^{17}$ Since the methodology tests correlation but not causation, association between insurance coverage and losses may be attributable to either adverse selection or moral hazard. 
Depending on the empirical observation $I N S_{i}$ of individual $i$, the residual in Eq. (3) will equal either the factor $\mathrm{A}\left(I N S_{i}=1\right)$ or the factor B $\left(I N S_{i}=0\right)$. Analogously, the residual $\eta_{i}$ from Model (2) can be estimated for each individual $i$. Then, the hypothesis $\rho\left(\hat{\varepsilon}_{i}, \hat{\eta}_{i}\right)=0$ can be tested. A positive correlation coefficient, as occurs in this study, indicates the presence of asymmetric information, which suggests adverse selection because individuals having insurance are more likely to need care. If adding one particular type of private information to vector $\mathbf{D}$ as an explanatory variable substantially reduces the correlation $\rho$, it can be concluded that it is this type of private information that was responsible for the previous positive correlation between INS and CARE and thus is one source of adverse selection. On the contrary, if adding a particular type of private information variable to vector $\mathbf{D}$ increases the correlation $\rho$, this private information should have caused the previous negative correlation between INS and CARE and thus should be a source of advantageous selection. We define the reduction (raise) in correlation after adding one type of private information as Property 1 of sources of adverse (advantageous) selection.

Generally, adverse selection occurs if individuals possess private information that (i) makes them more likely to purchase insurance and (ii) reveals to them they are aboveaverage risks. As a consequence, direct evidence of adverse selection is found if the coefficients of one type of private information in Eqs (1) and (2) are both positive. Analogously, advantageous selection occurs if some characteristics of individuals (i) make them more likely to purchase insurance and (ii) are negatively correlated with risk occurrence. ${ }^{14}$ These features suggest that the coefficients of the information variable in Eq. (1) should be positive and the coefficient in Eq. (2) negative. We specify these features as Property 2 of sources of adverse or advantageous selection.

\section{Data and variable settings}

\section{Insurance ownership and ex post care needs}

Our data are from the German Socio-Economic Panel (SOEP), a longitudinal panel dataset of households in Germany. The SOEP study was initiated in 1984 and originally surveyed 6,000 households and more than 12,000 respondents, with annual surveys of the same households (via household questionnaire) and persons (via individual questionnaire) thereafter. SOEP data records individuals' biographical history and cover objective (e.g. income and employment) as well as subjective (e.g. health and life satisfaction) indicators.

The individual questionnaire in 1992 is the only one in the SOEP study that asked respondents whether they owned private LTC insurance and thus, the answers to this question are used to define private LTC insurance ownership (INS).

Social LTC insurance in Germany was introduced in 1995. The programme became fully operational in 1996. Social LTC insurance is compulsory and consists of two forms, public LTC insurance and mandatory private LTC insurance. In 1996, approximately 9.6 per cent of the German population, roughly 7.9 million people, held mandatory private LTC insurance. ${ }^{18}$ Since social LTC insurance covers less than half the cost of institutional care on average, many individuals purchase private complementary LTC insurance as a supplement.

\footnotetext{
${ }^{18}$ PKV (1998).
} 
More information on the German LTC insurance system can be found in Geraedts et al. ${ }^{19}$ and Zhou-Richter et al. ${ }^{20}$

To track whether respondents became dependent and made use of LTC insurance, we chose this question from the household questionnaires: "Do you or another member of the household currently receive benefits from social LTC insurance?" Since benefits from social LTC insurance are made based on care levels defined in the German Social Security Code, it is reasonable to employ the existence of benefit payments from social LTC insurance to proxy ex post care needs. ${ }^{21}$

The data record the survey year of individuals' need for care as well as the care level required at that time. Respondents reported the level of care needed, if care was needed, by reporting one of the following:

1. Help is needed with chores/shopping outside of household.

2. Help is needed with household chores, meals, and drinking.

3. Help is required with simple personal care tasks, such as dressing and bathing.

4. Confined to bed (bed-ridden) on a long-term basis, and/or needs help with difficult personal care tasks, moving to another bed, going to the toilet, etc.

We define a variable_- "maximum care level"-by taking the maximum value of the reported care levels of a respondent in the period $1996-2006 .{ }^{22}$ In addition, we define a variable- "care duration"- as the sum of the number of years a person needed care to measure the length of dependency. If a respondent did not need care during the 11-year period, both variables_- "maximum care level" and "care duration"- are assigned the value 0 .

The data report the actual need for care from 1996 through 2006 for both insureds and uninsureds. Therefore, if an individual has received payment from social LTC insurance for at least one year between 1996 and 2006, the variable CARE is coded 1; if the individual has never received a payment during this time period, CARE is coded 0 . The sample used in this study thus contains the individuals for whom we can observe LTC insurance coverage in 1992 and their need (or lack of need) for LTC for the period 1996-2006. The disjointed nature of the data requires us to assume that individuals' LTC insurance status did not change between 1992 and 1996; that is, those who held insurance in 1992 continued to be insured in 1996, and those who did not have private coverage in 1992 did not acquire it. We also assume that individuals did not have losses prior to 1996. The effect on our results of the first assumption is ambiguous. The effect of the second is to bias against finding adverse selection in the market.

\section{Insurers' risk classification criteria}

If there is asymmetric information between the parties in an insurance market, the parties to a transaction by definition have different knowledge sets with which to evaluate the risk. LTC

19 Geraedts et al. (2000).

20 Zhou-Richter et al. (2010).

${ }^{21}$ Besche (2003).

22 The data used for this study were extracted from SOEP yearly surveys in 2008 with funding support from a university research award. 


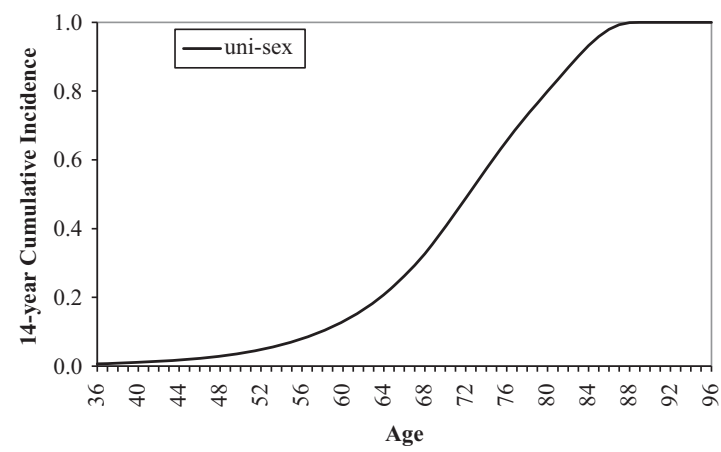

Figure 1. Unisex 14-year cumulative care incidence based on 1992 German incidence table for care.

insurers usually measure the LTC risk of potential insureds by age and gender. The practice in Germany in 1992 was to use the 1992 LTC incidence table, which was approved by the German Federal Supervisory Agency for Insurance (BAV), to calculate premiums and policy reserves for LTC insurance products. ${ }^{23}$ The 1992 table contains age-specific but sexindependent incidence rates for care needs.

Using the 1992 incidence table, we reproduce the insurers' prediction of the probability that a healthy individual becomes dependent. Let $i(x)$ describe the annual incidence of becoming dependent for an individual aged $x$ in 1992. The cumulative incidence over the period 1992 through 2006 (I) for an individual is then: ${ }^{24}$

$$
I(x)_{1992-2006}=1-\prod_{j=1}^{14}[1-i(x+j)] .
$$

In addition, we restrict the study's sample to those respondents aged 36 and older in 1992 who were at least 40 years old in 1996, the starting year of the care need observations. Figure 1 presents the uni-sex 14-year cumulative incidence for different age groups.

The insurance application forms of several leading LTC insurance providers in Germany require applicants to answer questions about their health condition. Responses are used in making coverage and pricing decisions. In the 1992 SOEP questionnaire, respondents were asked to answer similar questions about their health condition, which allows us to proxy the insurers' risk classification criteria. Specifically, the criteria are: (1) whether the respondent has an officially recognised disability $(D I S)$; (2) whether the respondent suffers from chronic pain or illness $(\mathrm{CHR})$; and (3) how many nights the respondent stayed in a hospital in 1991 (HOS).

The insurance application forms usually also include questions about applicants' existing or former insurance coverage, for instance, whether they have/had public health insurance or private substitute health insurance and, if so, where and when they are/were insured and what the policy number is/was. Legally, every German citizen should be insured by the public

${ }^{23}$ BAV (1992), Grupp et al. (1992).

${ }^{24}$ Eq. (4) ignores the possibility that a healthy person dies without needing LTC. This form of calculating the cumulative incidence is adjusted to fit the characteristics of the individuals in this study's selected sample, that is, only respondents who survived until the care need observation period are included in the selected sample. 
health insurance. Only certain segments of the German population, such as employees with annual incomes above the social security ceiling, public servants, the self-employed, and freelancers, are exempt from the public health insurance programme and are expected to purchase private substitute health insurance. The differentiation between public and private substitute health insurance ownership could be used by insurers in calculating the insurance premium, since insurers are of the opinion that the insureds in private substitute programmes have significantly lower care-needing risks than the publicly insured, as shown by the data collected from German substitute health insurance providers. ${ }^{25}$ We therefore consider the existence of substitute health insurance $(S U B)$, which can be generated from the SOEP data in 1992, as another risk classification criterion employed by insurers. In the final sample, there are 412 respondents (11 per cent of the total 3,749 respondents) who had private substitute health insurance in 1992.

\section{Potential sources of adverse selection}

To discover sources of adverse selection, we need to consider which private information suggests to individuals an increased probability of their needing care and thus makes them more likely to purchase LTC insurance.

Viewing respondents' own assessment of their health status as a source of adverse selection is intuitively appealing because people with private information about their poor health, even though not yet manifest in the form of disease, could have higher expectations of future dependency and therefore have higher current demand for LTC insurance. In the SOEP questionnaires, respondents were asked: "How would you describe your current health status?" Respondents could choose between (1) very good, (2) good, (3) satisfying, (4) not good, or (5) bad. Since it is the source of adverse selection that is of interest here, we use answers to this question as a negatively phrased categorical variable- "self-assessed poor health"-with 1 indicating "self-assessed very good health" to 5 indicating "selfassessed bad health". We expect respondents with self-assessed bad health are more likely to purchase insurance and also more likely to need care.

Some empirical studies have found that engaging in physical activity can reduce the risk of chronic disease and improve mental health. ${ }^{26}$ In comparison to the first variable, which is a subjective evaluation of health, the frequency of engaging in active sports objectively measures the individual's effort to improve his or her health. The survey question is: "How often do you play active sports in your spare time?" Respondents could choose either (1) every week, (2) every month, (3) more infrequently, or (4) never. We thus code the frequency of physical activity as a categorical and, again, negatively phrased variable — "infrequency of engaging in active sports"-with the highest value, 4, indicating never engaging in active sports.

We include responses to the question, "How do you evaluate your financial coverage in case LTC becomes necessary?" to indicate how well individuals feel they are prepared should the need for LTC arise. Answers to this question may be influenced by wealth, with richer people, all else equal, feeling better prepared. Answers may also be influenced by risk aversion, with more risk-averse individuals, all else equal, feeling less well prepared.

\footnotetext{
25 DAV (2009).

${ }^{26}$ WHO (2001), DH (2004).
} 
612

Moreover, answers may also be influenced by the purchase of LTC insurance. All else equal, we expect that individuals who report that they are better prepared financially have purchased LTC insurance. We hypothesise that individuals who report being better prepared have given greater thought to the risk than others and that their greater concern about the risk is indicative of a greater likelihood of needing care. An alternative hypothesis is that those who give the risk greater thought are more likely to take preventative steps to avoid the risk becoming a loss. In this case, a negative relationship between care and reporting being financially better prepared for the risk would be expected, all else equal. Survey participants reported how well they felt they were prepared financially for the risk on a scale of (1) - (6), with (1) representing the strongest sense of being financially prepared and (5) the worst. Individuals answered (6) if they felt that they did not know how well prepared they were. Individuals who answered (1) very good, (2) good, or (3) satisfactory were classified for this study as "self-assessed prepared", while those who answered (4) not good or (5) bad were classified as "selfassessed unprepared". Finally, those individuals who answered (6) were classified as "self-assessed unaware". Two dummy variables are defined, respectively, for the group "self-assessed prepared" and "self-assessed unaware", while the group "self-assessed unprepared" serves as the control group.

Two theoretical works-Pauly ${ }^{27}$, and Zweifel and Strüwe ${ }^{28}$ - suggest that informal care provided by family members may substitute for nursing home care and thus reduce individuals' incentive to purchase LTC insurance. Finkelstein and McGarry ${ }^{8}$ empirically show that individuals who have more children are less likely to use nursing home care. However, to our knowledge, there is no evidence reported in the literature on how the presence of potential informal caregivers impacts the general (both institutional and informal) need for care. To measure the unavailability of informal caregivers, we first define a binary variable representing marital status, with the value 1 denoting respondents who are either not married or else married but not living with their spouse. We use another categorical variable to indicate respondents' number of children, which is coded as follows: (1) five or more children, (2) four children, (3) three children, (4) two children, (5) one child, and (6) no children.

\section{Potential sources of advantageous selection}

The most prominent source of advantageous selection is individuals' level of risk aversion. Barksy et al. ${ }^{29}$, for instance, link risk aversion to insurance consumption. Since there is no direct question asked in the 1992 SOEP questionnaire about respondents' risk aversion, this paper employs three factors related to risk aversion to measure advantageous selection: individuals' level of pessimism, preference for insurance, and personal income.

Koufopoulos ${ }^{30}$ and Sandroni and Squintani ${ }^{31}$ report evidence that compared to optimistic people, pessimistic individuals tend to overestimate the probability of risk occurrence.

\footnotetext{
27 Pauly (1990).

${ }^{28}$ Zweifel and Strüwe (1998).

29 Barksy et al. (1997).

${ }^{30}$ Koufopoulos (2008).

${ }^{31}$ Sandroni and Squintani (2007).
} 
Therefore, his theoretical model suggests that pessimistic individuals should purchase more insurance and also undertake more precautionary measures. To measure respondents' levels of pessimism, we use three questions from the 1992 SOEP questionnaire: (1) "Are you concerned about the development of the general economy?" (2) "Are you concerned about the protection of the environment?" (3) "Are you concerned about peace in the world?" To answer each of these questions, respondents could choose either (1) no concern, (2) some concern, or (3) great concern. Since these three concerns are subjective and nonself-relevant, respondents reporting more concerns attribute higher probabilities to these general risks and can thus be viewed as more pessimistic than those who report fewer, if any, concerns. Another possibility is that concern about the issues raised in these questions is indicative of greater cognitive ability. Fang et al. ${ }^{14}$ find that cognitive ability is associated with advantageous selection. The test variable takes the integer mean of the three answers and is measured on a scale from 1 to 3 , with 1 indicating low pessimism and 3 indicating high pessimism.

Another way we test for advantageous selection is by investigating preference for insurance, proxied by ownership of complementary health insurance. ${ }^{32}$ In Germany, in addition to public or private substitute health insurance, people can purchase complementary private health insurance policies to protect themselves, for example, against the high cost of dental prostheses or to upgrade their hospital accommodations. After controlling for individuals' health risks, those with complementary health insurance should have a higher preference for insurance in general than those without it. These individuals with higher preference for insurance are also expected to have fewer ex post health risks under the assumption that security-seeking individuals behave more cautiously. In the final sample, 47 respondents (about 1.25 per cent) have complementary health insurance. We define a binary variable_- "preference for insurance"-with 1 indicating possession of complementary private health insurance and thus a high preference for insurance.

Since the social welfare programme in Germany is the last resort for the uncovered LTC costs of the poor, it is likely that individuals with greater wealth have a higher demand for LTC insurance than individuals with limited financial resources. On the other hand, wealthier people are less likely to use nursing home care according to Finkelstein and McGarry. ${ }^{8}$ We proxy wealth by averaging reported income over the five-year period 1988 through 1992.

\section{Data description}

In 1992, 7,020 respondents answered the question about ownership of private LTC insurance in the SOEP individual questionnaire. We eliminate from this group 747 respondents who did not participate in any of the 11 surveys in the period 1996-2006 because their need for LTC is not observable. In addition, 2,457 respondents who were younger than 36 years in 1992 are excluded due to our sample selection based on the 1992 LTC incidence table (see section "Insurer's risk classification criteria"). We further exclude 67 respondents who were already care-needing in 1992, ending with a final sample of 3,749 respondents.

In this final sample of 3,749 respondents, 66 (1.76 per cent) had private LTC insurance in 1992; 162 (4.32 per cent) became dependent in the period 1996-2006.

\footnotetext{
${ }^{32}$ Einav et al. (2012) and Barseghyan et al. (2011) consider risk preferences across insurance contracts.
} 
Table 1 Summary statistics of respondents' need for care of uninsured group, insured group, and total sample $(3,749$ respondents)

\begin{tabular}{|c|c|c|c|c|c|c|}
\hline \multirow[t]{3}{*}{ Variable } & \multicolumn{4}{|c|}{ Private LTC insurance in 1992} & & \\
\hline & \multicolumn{2}{|c|}{ No $(\mathrm{N}=3,683)$} & \multicolumn{2}{|c|}{ Yes $(\mathrm{N}=66)$} & \multicolumn{2}{|c|}{$\operatorname{All}(\mathrm{N}=3,749)$} \\
\hline & Mean & S.E. & Mean & S.E. & Mean & S.E. \\
\hline Need for LTC in the period $1996-2006(0=$ no, $1=$ yes $)$ & 0.04 & $(0.20)$ & 0.06 & $(0.24)$ & 0.04 & $(0.20)$ \\
\hline Maximum care level $(1=$ low through $4=$ high $)$ & 0.17 & $(0.86)$ & 0.21 & $(0.92)$ & 0.18 & $(0.86)$ \\
\hline Years care was needed & 0.11 & $(0.66)$ & 0.15 & $(0.66)$ & 0.11 & $(0.66)$ \\
\hline
\end{tabular}

Table 2 Summary statistics of insurers' risk classification criteria (3,749 respondents)

\begin{tabular}{llrrrrr}
\hline Variable & Type & Mean & S.E. & Min. & Max. & Obs \\
\hline Age & Numerical & 54.10 & 12.45 & 36 & 93 & 3,749 \\
Gender (1=male) & Binary & 0.46 & 0.50 & 0 & 1 & 3,749 \\
Disabled (1=yes) & Binary & 0.17 & 0.37 & 0 & 1 & 3,706 \\
Suffer from chronic illness (1=yes) & Binary & 0.37 & 0.48 & 0 & 1 & 3,728 \\
Number of nights stayed in hospital in 1991 & Numerical & 2.24 & 10.58 & 0 & 365 & 3,744 \\
Ownership of private substitute health insurance (1=yes) & Binary & 0.11 & 0.31 & 0 & 1 & 3,749 \\
\hline
\end{tabular}

Table 1 presents summary statistics on respondents' need for care, at first separately for the uninsured and insured groups based on LTC insurance ownership observed in 1992, and then for the total sample. The results show that all three variables measuring respondents' need for care - the likelihood of needing care, the maximum care level, and the number of years care was needed-have higher values for the insured respondents than for the uninsured ones, on average. However, the independent samples $T$ tests show that the means of these three variables for the insured and uninsured groups are not significantly different from each other.

Table 2 reports summary statistics (mean, standard error, minimum, maximum, and number of observations) for the variables proxying insurers' risk classification criteria.

As shown in Table 2, the average age of respondents in 1992 reported in the data is 54, and 46 per cent are reported as males. Probably because of the advanced average age, almost onefifth of the respondents were officially recognised as disabled and more than one-third suffered from chronic pain and illness.

Table 3 sets forth summary statistics for the variables considered to be potential sources of adverse and advantageous selection.

The summary statistics for private information variables show that an average respondent engaged in active sports less frequently than once every month, evaluated his or her current health as "satisfying", had a quite high level of pessimism, and earned €790 per month from 1988 through 1992. Twenty-eight per cent of respondents assessed their LTC risk as high, based on their judgement that their financial coverage in case of needing care was good. Few respondents ( 24 per cent) were not married or not living with their spouse. Only 1 per cent of respondents exhibited a high preference for insurance by owning complementary health insurance. The average number of children was less than one. 
Table 3 Summary statistics of potential sources of adverse and advantageous selection $(3,749$ respondents)

\begin{tabular}{|c|c|c|c|c|c|c|}
\hline Variable & Type & Mean & S.E. & Min. & Max. & Obs \\
\hline $\begin{array}{l}\text { Infrequency of engaging in active sports (frequency: } 1=\text { every week, } \\
2=\text { every month, } 3=\text { more infrequently, } 4=\text { never) }\end{array}$ & Categorical & 3.09 & 1.22 & 1 & 4 & 3,651 \\
\hline $\begin{array}{l}\text { Self-assessed poor health }(1=\text { very good health, } 2=\text { good health, } \\
3=\text { satisfying health, } 4=\text { not good health, } 5=\text { bad health })\end{array}$ & Categorical & 2.71 & 0.95 & 1 & 5 & 3,745 \\
\hline Marital status ( $1=$ not married or not living with spouse $)$ & Binary & 0.24 & 0.43 & 0 & 1 & 3,749 \\
\hline $\begin{array}{l}\text { Having fewer children }(1=5 \text { or more children, } 2=4 \text { children, } 3=3 \\
\text { children, } 4=2 \text { children, } 5=1 \text { child, } 6=\text { no children })\end{array}$ & Categorical & 5.51 & 0.89 & 1 & 6 & 3,749 \\
\hline Self-assessed prepared for LTC risk ( $1=$ yes) & Binary & 0.28 & 0.45 & 0 & 1 & 3,563 \\
\hline Self-assessed unaware of LTC risk ( $1=$ yes) & Binary & 0.17 & 0.37 & 0 & 1 & 3,563 \\
\hline Average monthly income (in $€ 1,000$ ) & Numerical & 0.79 & 0.45 & 0.15 & 7.93 & 3,686 \\
\hline Pessimism ( $1=$ low, $2=$ middle, $3=$ high $)$ & Categorical & 2.57 & 0.58 & 1.00 & 3.00 & 3,749 \\
\hline Preference for insurance ( $1=$ high $)$ & Binary & 0.01 & 0.11 & 0.00 & 1.00 & 3,749 \\
\hline
\end{tabular}

\section{Empirical results}

\section{Predictive power of insurers' risk classification criteria}

As previously discussed, insurers base their risk classification on predicted LTC incidences and insurance application information. To examine how well the proxies for insurers' risk classification criteria used in this paper predict ex post care need, we estimate the following model:

$$
\operatorname{Prob}(C A R E)=\Phi\left(\beta_{1} I+\beta_{2} D I S+\beta_{3} C H R+\beta_{4} H O S+\beta_{5} S U B\right),
$$

where CARE indicates whether the individual needed care for at least 1 year during the 11 years from 1996 to 2006. To identify whether the risk classification criteria can also predict the intensity and duration of care need, we further regress the two variables introduced in the section "Insurance ownership and ex post care needs"-(1) the person's maximum care level and (2) how many years a person needed care-on the explanatory variables in Eq. (5).

The first three columns of Table 4 report the predictive power of insurers' risk classification criteria for ex post care need. As can be seen from Table 4, the cumulative care incidence for the period 1992-2006 calculated on the basis of the German incidence table is influential for all three measurements of ex post care need-the likelihood of becoming dependent, the maximum care level and the number of years care is needed-at a high level of significance. All the variables proxying for application information-current disability, existence of chronic illness, and the number of nights one stayed in a hospital-are also significantly positively correlated with care need according to at least one measurement of ex post care need. The negative signs of private substitute health insurance in the first three columns indicate that respondents with substitute health insurance are less likely to become dependent than are respondents with solely public health insurance.

In summary, the cumulative care incidence and other application information variables are powerful predictors of ex post care need as well as of care intensity and duration. The risk classification criteria, proxied as described above with the SOEP data, do well at differentiating between risk types. 
Table 4 Predictive power of insurers' risk classification criteria for ex post care need and their influence on insurance coverage

\begin{tabular}{lcccc}
\hline & $\begin{array}{c}\text { Need for LTC in the period } \\
\text { 1996-2006 }\end{array}$ & $\begin{array}{c}\text { Maximum } \\
\text { care level }\end{array}$ & $\begin{array}{c}\text { Years care was } \\
\text { needed }\end{array}$ & $\begin{array}{c}\text { LTC insurance } \\
\text { ownership }\end{array}$ \\
\hline 14-year cumulative care & $1.541^{* * *}$ & $0.861^{* * *}$ & $0.523^{* * * *}$ & $-1.094^{* * *}$ \\
incidence & $(0.000)$ & $(0.000)$ & $(0.000)$ & $(0.008)$ \\
Disabled & $0.200^{* *}$ & 0.066 & 0.034 & -0.120 \\
& $(0.036)$ & $(0.104)$ & $(0.274)$ & $(0.505)$ \\
Suffer from chronic illness & $0.270^{* * *}$ & $0.093^{* * *}$ & $0.071^{* * *}$ & -0.084 \\
Number of nights spent in & $(0.002)$ & $(0.003)$ & $(0.004)$ & $(0.495)$ \\
hospital in 1991 & $0.007^{* * *}$ & $0.005^{* * *}$ & $0.004^{* * *}$ & 0.002 \\
Ownership of private substitute & $(0.009)$ & $(0.000)$ & $(0.000)$ & $(0.620)$ \\
health insurance & $-0.362^{* *}$ & -0.059 & -0.027 & $0.326^{* *}$ \\
& $(0.041)$ & $(0.177)$ & $(0.423)$ & $(0.012)$ \\
$N$ & & & & \\
Pseudo- $R^{2}$ & 3,685 & 3,685 & 3,685 & 3,685 \\
$R^{2}$ & & 0.066 & 0.045 & 0.033 \\
\hline
\end{tabular}

$p$-values in parentheses.

$* * p<0.05, * * * p<0.01$.

The last column of Table 4 shows whether these risk classification criteria in fact hindered individuals from purchasing LTC insurance. The cumulative care incidence is negatively correlated with LTC insurance ownership and is significant at the 5 per cent level, suggesting that care-incidence-based insurance premiums with usually proportional safety and cost loading helped insurers select better-risk types. The positive correlation between private substitute health insurance ownership and LTC insurance ownership could be due to insurers being more willing to extend coverage to owners of private substitute health insurance, who have, based on insurers' experience, a lower risk of needing care. This positive correlation, though, could also be the result of cross-selling by insurance agents. The other risk classification criteria are mostly, as expected, negatively correlated with LTC insurance ownership; however, these correlations are not significant. This fact should not be taken to imply that the other risk classification criteria have no influence on underwriting, because LTC insurance policies could have been purchased years ago when the individuals were healthier and, for instance, were not disabled.

The question of whether the problem of adverse selection is eliminated through the underwriting process can be answered by the positive correlation tests for asymmetric information discussed earlier. This is the subject of the next section.

\section{Evidence of adverse and advantageous selection}

In this section, we undertake the approach described in the section "Econometric properties of sources of adverse and advantageous selection" to identify sources of adverse and advantageous selection. We first examine the correlation between LTC insurance ownership 
and ex post care need, conditional on insurers' risk classification criteria. For this purpose, the bivariate probit model in Eqs (1) and (2) is estimated, where the vector of explanatory variables $\mathbf{D}$ includes insurers' risk classification criteria as presented in Eq. (5). As the next step, we gradually add sources of adverse selection to vector $\mathbf{D}$ and report the results of binary probit models in Table 5. The table reports that several of the variables have a significant correlation with insurance consumption, although the magnitudes of the coefficients in these cases are not great. Finally, the sources of advantageous selection are added to the binary probit model; the results are reported in Table 6.

The probit models are estimated via the maximum likelihood method. Even though the risk classification variables are included in all models, Tables 5 and 6 present only the point estimates and standard errors for the coefficients of the variables suggesting adverse and advantageous selection. The tables also report the sample size and pseudo- $R^{2}$ for each regression model. The declining number of observations is due to an increasing number of missing values as more variables are added to the regression. The last two rows in the tables present the correlations between the two residuals from the bivariate models and the $p$-values of the independence tests.

As reported in the columns under Model (5.0) in Table 5, the correlation between two residuals - and thus the correlation between insurance (INS) and risk (CARE) - is positive at a significance level of 5 per cent, indicating that when facing the same set of insurance premiums defined according to insurers' risk classification criteria, respondents who purchased LTC insurance were indeed more likely to need care compared to those who did not buy LTC insurance. This positive correlation provides evidence that there is private information and suggests there is adverse selection occurring in the market.

As discussed in the section "Econometric properties of sources of adverse and advantageous selection", a form of private information is a possible source of adverse selection if this information is positively correlated with both insurance coverage and ex post care need. If we extract one source of adverse selection from the individuals' private information set and add it as an explanatory variable to the regression, we would expect the positive correlation caused by the remaining private information to decrease.

In Models (5.1)-(5.5) of Table 5, we estimate five bivariate probit models by gradually adding one additional possible source of adverse selection to the regression of Model (5.0). The rows under Models (5.1)-(5.5), therefore, display a list of sources of adverse selection included in the vector of explanatory variables $\mathbf{D}$, with (no) reported regression coefficients and standard errors indicating that a particular variable is (not) included. For example, the vector of explanatory variables D for Model (5.1) includes not only insurers' risk classification criteria, but also the infrequency of engaging in active sports.

In comparison to the starting Model (5.0), which only includes insurers' risk classification criteria, the positive correlation between two residuals $\rho(\varepsilon, \eta)$ in Models (5.1)-(5.5) decreases, either in the form of a decreasing correlation coefficient or in the form of an increasing $p$-value. This result satisfies Property 1 for adverse selection and provides evidence for concluding that the five dimensions of private information-infrequency of engaging in active sports, self-assessed poor health, not being married or married but not living with the spouse, having fewer children, and self-assessed as prepared for the LTC risk - are actual sources of adverse selection.

Among the sources of adverse selection, extracting the two dummy variablesself-assessed prepared and self-assessed unaware-makes the correlation between insurance 
Table 5 Sources of adverse selection and their impact on the correlation between LTC insurance ownership and actual care need

\begin{tabular}{|c|c|c|c|c|c|c|c|c|c|c|c|c|}
\hline & \multirow{2}{*}{\multicolumn{2}{|c|}{$\frac{\text { Original }}{\text { Model }(5.0)}$}} & \multicolumn{10}{|c|}{ Gradual addition of sources of adverse selection } \\
\hline & & & \multicolumn{2}{|c|}{ Model (5.1) } & \multicolumn{2}{|c|}{ Model (5.2) } & \multicolumn{2}{|c|}{ Model (5.3) } & \multicolumn{2}{|c|}{ Model (5.4) } & \multicolumn{2}{|c|}{ Model (5.5) } \\
\hline & $\begin{array}{c}\text { LTC } \\
\text { insurance } \\
\text { ownership }\end{array}$ & $\begin{array}{c}\text { Expost } \\
\text { care } \\
\text { need }\end{array}$ & $\begin{array}{c}\text { LTC } \\
\text { insurance } \\
\text { ownership }\end{array}$ & $\begin{array}{c}\text { Ex post } \\
\text { care } \\
\text { need }\end{array}$ & $\begin{array}{c}\text { LTC } \\
\text { insurance } \\
\text { ownership }\end{array}$ & $\begin{array}{l}\text { Ex post } \\
\text { care need }\end{array}$ & $\begin{array}{c}\text { LTC } \\
\text { insurance } \\
\text { ownership }\end{array}$ & $\begin{array}{c}\text { Ex post } \\
\text { care need }\end{array}$ & $\begin{array}{c}\text { LTC } \\
\text { insurance } \\
\text { ownership }\end{array}$ & $\begin{array}{c}\text { Expost } \\
\text { care need }\end{array}$ & $\begin{array}{c}\text { LTC } \\
\text { insurance } \\
\text { ownership }\end{array}$ & $\begin{array}{c}\text { Ex post } \\
\text { care need }\end{array}$ \\
\hline $\begin{array}{l}\text { Infrequency of engaging } \\
\text { in active sports }\end{array}$ & & & $\begin{array}{c}0.048 \\
(0.044)\end{array}$ & $\begin{array}{l}0.090 * * \\
(0.039)\end{array}$ & $\begin{array}{c}0.051 \\
(0.045)\end{array}$ & $\begin{array}{c}0.057 \\
(0.041)\end{array}$ & $\begin{array}{c}0.052 \\
(0.045)\end{array}$ & $\begin{array}{c}0.059 \\
(0.041)\end{array}$ & $\begin{array}{c}0.052 \\
(0.045)\end{array}$ & $\begin{array}{c}0.058 \\
(0.041)\end{array}$ & $\begin{array}{c}0.043 \\
(0.047)\end{array}$ & $\begin{array}{c}0.056 \\
(0.043)\end{array}$ \\
\hline health & & & & & $(0.067)$ & $(0.051)$ & $(0.067)$ & $(0.051)$ & $(0.067)$ & $(0.051)$ & $(0.071)$ & $(0.054)$ \\
\hline $\begin{array}{l}\text { Not being married or not } \\
\text { living with spouse }\end{array}$ & & & & & & & $\begin{array}{c}0.151 \\
(0.121)\end{array}$ & $\begin{array}{l}0.217 * * \\
(0.091)\end{array}$ & $\begin{array}{c}0.162 \\
(0.123)\end{array}$ & $\begin{array}{l}0.198 * * \\
(0.091)\end{array}$ & $\begin{array}{c}0.066 \\
(0.138)\end{array}$ & $\begin{array}{l}0.213 * * \\
(0.097)\end{array}$ \\
\hline Having fewer children & & & & & & & & & $\begin{array}{c}-0.032 \\
(0.056)\end{array}$ & $\begin{array}{l}0.257 * * \\
(0.102)\end{array}$ & $\begin{array}{c}-0.011 \\
(0.059)\end{array}$ & $\begin{array}{l}0.257^{* *} \\
(0.106)\end{array}$ \\
\hline Self-assessed prepared & & & & & & & & & & & $\begin{array}{l}0.477 * * * \\
(0.122)\end{array}$ & $\begin{array}{c}0.181 * \\
(0.102)\end{array}$ \\
\hline Self-assessed unaware & & & & & & & & & & & $\begin{array}{c}0.121 \\
(0.167)\end{array}$ & $\begin{array}{c}0.080 \\
(0.126)\end{array}$ \\
\hline Pseudo- $R^{2}$ & 0.033 & 0.143 & 0.036 & 0.151 & 0.037 & 0.175 & 0.039 & 0.179 & 0.040 & 0.185 & 0.074 & 0.180 \\
\hline $\begin{array}{l}\text { Correlation between } \\
\text { two residuals } \rho(\varepsilon, \eta)\end{array}$ & \multicolumn{2}{|c|}{$\begin{array}{c}0.033 * * \\
{[p=0.046]}\end{array}$} & \multicolumn{2}{|c|}{$\begin{array}{c}0.032^{*} \\
{[p=0.056]}\end{array}$} & \multicolumn{2}{|c|}{$\begin{array}{c}0.032 * \\
{[p=0.058]}\end{array}$} & \multicolumn{2}{|c|}{$\begin{array}{c}0.031 * \\
{[p=0.062]}\end{array}$} & \multicolumn{2}{|c|}{$\begin{array}{c}0.031^{*} \\
{[p=0.065]}\end{array}$} & \multicolumn{2}{|c|}{$\begin{array}{c}0.014 \\
{[p=0.396]}\end{array}$} \\
\hline
\end{tabular}

$* * * p<0.01, * * p<0.05, * p<0.10$ (two-tailed tests).

Notes: (1) Standard errors in parentheses.

(2) Risk classification variables are included in all models. 
and risk substantially indistinguishable from zero. The coefficients of the variable "selfassessed prepared" in the bivariate probit Model (5.5) are also significantly positive when all sources of adverse selection are included in the vector $\mathbf{D}$, indicating that the respondents assessing themselves financially well prepared for LTC risk are significantly more likely to have insurance and become dependent. Our analysis indicates this is the most important dimension of private information that results in adverse selection. The hypothesis that individuals who are aware of their higher risk of becoming dependent expend more effort to protect themselves from future financial distress by, for example, purchasing LTC insurance policies is, therefore, supported by empirical evidence.

The other two sources of adverse selection-infrequency of engaging in active sports and not being married or not living with one's spouse-are, as expected, positively correlated with LTC insurance ownership and ex post care need. Their estimated coefficients in regressions on the care need $(C A R E)$ are significant at the 5 per cent level (in at least one model), showing that people are more likely to become care-needing if they engage less frequently in active sports or are not married or not living with their spouse. However, the positive influence of these two variables on demand for LTC insurance (INS) is not significant.

Another interesting result is that people with fewer children are more likely to become dependent, whereas the number of children apparently has no significant impact on the decision to purchase insurance.

Self-assessed poor health implies a high probability of needing LTC, as the highly significant positive coefficient of this variable confirms. It is reasonable to expect that after controlling for risk classification criteria observable by insurers, how one assesses one's health status should be associated with the decision to purchase insurance. Nonetheless, the coefficients of this variable in the regression model INS are not only insignificant, they also have the wrong signs - negative signs, indicating that individuals who assess their health as poor do not have a higher demand for LTC insurance than individuals who consider themselves healthy.

The weak impact of self-assessed poor health on insurance demand echoes the empirical results in Zhou-Richter et al. ${ }^{20}$, who find strong evidence that demand for LTC insurance is suppressed by people's ignorance of LTC risk. A comparison of the different impact between assessment of LTC risk and assessment of health status suggests that, among respondents with private information about their poor health, some seem to be aware of LTC risk and thus have purchased insurance, whereas others do not seem to be aware of this risk and have not purchased insurance.

Table 6 reports the results of testing the sources of advantageous selection. Starting from Model (5.0), which only includes insurers' risk classification criteria as explanatory variables, Models (6.1)-(6.3) gradually add three sources of advantageous selection to the bivariate probit model-respondents' average monthly income, their levels of pessimism, and their preference for insurance.

A source of advantageous selection would be one that is positively correlated with insurance demand but negatively correlated with risk. If we extract one source of advantageous selection from the private information set, we would expect the original positive correlation between two residuals $\rho(\varepsilon, \eta)$ in Model (5.0) to increase.

As can be seen from the last two rows in Table 6, the correlation between insurance and risk increases and the $p$-value shrinks after adding each type of private information. These 
Table 6 Sources of advantageous selection and their impact on the correlation between LTC insurance ownership and actual care need

\begin{tabular}{|c|c|c|c|c|c|c|c|c|}
\hline & Origi & & $G r$ & dual addi & tion of sourc & es of advant & geous select & ion \\
\hline & Model & $5.0)$ & Model & $6.1)$ & Mode & $l(6.2)$ & Mode & $(6.3)$ \\
\hline & $\begin{array}{c}\text { LTC } \\
\text { insurance } \\
\text { ownership }\end{array}$ & $\begin{array}{c}\text { Ex post } \\
\text { care } \\
\text { need }\end{array}$ & $\begin{array}{c}\text { LTC } \\
\text { insurance } \\
\text { ownership }\end{array}$ & $\begin{array}{c}\text { Ex post } \\
\text { care } \\
\text { need }\end{array}$ & $\begin{array}{c}\text { LTC } \\
\text { insurance } \\
\text { ownership }\end{array}$ & $\begin{array}{c}\text { Ex post } \\
\text { care need }\end{array}$ & $\begin{array}{c}\text { LTC } \\
\text { insurance } \\
\text { ownership }\end{array}$ & $\begin{array}{c}\text { Ex post } \\
\text { care need }\end{array}$ \\
\hline Average income & & & 0.051 & 0.045 & 0.049 & 0.050 & 0.041 & 0.061 \\
\hline in $€ 1,000$ & & & $(0.098)$ & $(0.095)$ & $(0.100)$ & $(0.095)$ & $(0.100)$ & $(0.095)$ \\
\hline Pessimism & & & & & $0.184 *$ & $-0.171 * * *$ & $0.179 *$ & $-0.171 * * *$ \\
\hline & & & & & $(0.101)$ & $(0.063)$ & $(0.101)$ & $(0.063)$ \\
\hline Preference for & & & & & & & $0.695^{* * *}$ & $\rho^{\mathrm{a}}$ \\
\hline insurance & & & & & & & $(0.303)$ & $\rho^{\mathrm{a}}$ \\
\hline$N$ & 3,685 & 3,685 & 3,625 & 3,625 & 3,625 & 3,625 & 3,625 & 3,580 \\
\hline Pseudo- $R^{2}$ & 0.033 & 0.143 & 0.034 & 0.142 & 0.039 & 0.148 & 0.046 & 0.149 \\
\hline Correlation & 0.033 & & 0.033 & & 0.0 & $5 * *$ & 0.03 & $6^{* *}$ \\
\hline between two & {$[p=0.0$} & & {$[p=0$.} & & {$[p=0$} & $.036]$ & {$[p=0$} & $031]$ \\
\hline residuals $\rho(\varepsilon, \eta)$ & & & & & & & & \\
\hline
\end{tabular}

${ }^{\mathrm{a}}$ No coefficient estimated because $\mathrm{CARE}=0$ is predicted perfectly for the case where respondents have substitute health insurance (47 respondents).

$* * * p<0.01, * * p<0.05, * p<0.10$ (two-tailed tests).

Notes: (1) Standard errors in parentheses. (2) Risk classification variables are included in all models.

results satisfy Property 1 of advantageous selection and support expectations that income, pessimism, and preference for insurance are sources of advantageous selection.

We do not find a statistically significant relationship between wealth and insurance ownership or between wealth and the need for care.

The level of pessimism is significantly positively correlated with insurance coverage and negatively correlated with actual care need at the 5 per cent significance level. Therefore, this variable fulfils Property 2 of advantageous selection. These results are in accordance with the expectation that the more pessimistic an individual is, the higher will be his or her insurance demand, and the more cautiously he or she will behave, consequently lowering the probability of becoming dependent.

The preference for insurance, proxied by the ownership of complementary health insurance, is significantly positively associated with ownership of LTC insurance (INS). This variable, however, is automatically dropped while regressing on actual care need $(C A R E)$ in Model (6.3) because the case where respondents have complementary health insurance perfectly predicts the failure in the dependent variable, that is, $C A R E=0$. In other words, none of the 47 respondents who purchased complementary health insurance (with an average age of 54.7 years) became dependent during the observation period, whereas the dependency rate of non-purchasers (with an average age of 54.4 years) was about 5 per cent. These results provide strong evidence that purchasers of complementary health insurance de facto have much lower LTC risk. The ownership of complementary health insurance can be considered as fulfilling Property 2 and is thus an important source of advantageous selection. 
Table 7 Changes in correlation between LTC insurance and actual care need, estimated through five bivariate probit models

\begin{tabular}{|c|c|c|c|c|c|}
\hline \multirow[b]{3}{*}{ Model } & \multirow{3}{*}{$\begin{array}{c}\text { No } \\
\text { control } \\
\\
(7.1)\end{array}$} & \multicolumn{4}{|c|}{ Control for insurers' risk classification criteria } \\
\hline & & & $\begin{array}{l}\text { and for sources of } \\
\text { adverse selection }\end{array}$ & $\begin{array}{c}\text { and for sources of } \\
\text { advantageous selection }\end{array}$ & $\begin{array}{c}\text { and for all private } \\
\text { information }\end{array}$ \\
\hline & & $(7.2)$ & $(7.3)$ & $(7.4)$ & $(7.5)$ \\
\hline $\begin{array}{l}\text { Correlation between two } \\
\text { residuals } \rho(\varepsilon, \eta)\end{array}$ & $\begin{array}{c}0.011 \\
(0.483)\end{array}$ & $\begin{array}{l}0.033 * * \\
(0.046)\end{array}$ & $\begin{array}{c}0.014 \\
(0.396)\end{array}$ & $\begin{array}{l}0.036^{* *} \\
(0.031)\end{array}$ & $\begin{array}{c}0.017 \\
(0.329)\end{array}$ \\
\hline
\end{tabular}

To show the impact of insurers' risk classification criteria and individuals' private information on the relationship between LTC insurance ownership and actual care need, Table 7 summarises the correlations between the two residuals from the bivariate probit models, $\rho(\varepsilon, \eta)$. At first, the null hypothesis of independence of LTC insurance ownership and actual care need cannot be rejected in Model (7.1), which does not control for insurers' information set. This correlation between insurance and risk becomes significantly positive after controlling for all variables observed by insurers in Model (7.2), suggesting that when facing the same set of insurance premiums based on insurers' risk classification criteria, individuals who purchased LTC insurance are more likely to become dependent. While the extraction of sources of adverse selection from private information makes the former positive correlation now substantially indistinguishable from zero (Model (7.3)), the extraction of sources of advantageous selection slightly strengthens the positive correlation (Model (7.4)). When extracting all the private information, that is, assuming that all the private information is observable by insurers, LTC insurance ownership and actual care need become independent, suggesting that there is no strong selection effect left in the sample. The final independence shows that this study has successfully identified some key sources of adverse and advantageous selection.

\section{Conclusion and discussion}

Since LTC insurance products have existed for less than four decades and demand for them has been low, it is difficult for the insurance industry to forecast future LTC risk and calculate risk-adequate premiums and policy reserves. This study sheds some light on the differences between insureds' and uninsureds' LTC risk profiles. Conditional on insurers' assessment of individuals' risk types, this study first identifies a positive correlation between LTC insurance ownership and ex post care need based on German data, suggesting the presence of asymmetric information in the German private LTC insurance market.

Using bivariate probit models, the study successfully identifies five dimensions of individuals' private information that contribute to the positive correlation between LTC risk 
622

and insurance coverage-infrequency of engaging in active sports, self-assessed poor health, not being married or not living with one's spouse, having fewer children, and one's selfassessment of financial readiness should the need for nursing care arise. In addition, we find three dimensions of private information that contribute to the negative correlation between risk and insurance-individuals' income, pessimism level, and preference for insurance.

The fact that insurance and risk become independent after extracting the selection effect of the above-mentioned dimensions of private information provides evidence that this study successfully identifies some major sources of adverse and advantageous selection in the German private LTC insurance market. Among all the dimensions of private information, the sources of adverse selection have a dominating impact and make the correlation between insurance and risk significantly positive. The most powerful source of adverse selection is individuals' self-assessed financial readiness should the need for nursing care arise. Those who identify themselves as financially prepared for this risk are significantly more likely both to purchase LTC insurance and actually to need care. Concerning advantageous selection, more pessimistic people and those with a high preference for insurance are significantly more likely to have LTC insurance but are less likely to become dependent and thus need nursing care.

A further important finding of the study is that individuals' self-assessment of their health status has no powerful influence on the insurance purchasing decision, even though such an assessment predicts their ex post care need very well.

The findings of this study highlight the different effects of adverse and advantageous selection in the German private LTC insurance market: the "lemons principle" outweighs "cherry picking" and results in a positive correlation between risk and insurance. The dominating effect of adverse selection in the German private LTC insurance market gives support to the conventional claim that asymmetric information distorts market efficiency and results in lack of insurance demand. Our results contrast with Finkelstein and McGarry ${ }^{8}$ who do not find adverse selection in the U.S. LTC market. The fact that the studies focus on LTC markets in different countries with different regulatory regimes during different time periods likely explains the differences in the empirical findings.

Decomposing the private information into different dimensions makes it easier to predict the future development of correlation between LTC insurance ownership and actual care need. If, for instance, individuals' assessment of their health status becomes influential in their demand for LTC insurance, the positive correlation between insurance and risk, as observed in this study, would be stronger, assuming that the influence of other types of private information is stable. Such a situation could occur as people gradually become more aware of their future LTC risk, perhaps due to the influence of national debates over the financial problems facing public LTC programmes, such as the one taking place in Germany today. The predictive ability of the decomposition method responds to the appeal in Cohen and Siegelman ${ }^{33}$ that future work in testing adverse selection should be devoted to identifying the circumstances under which adverse selection arises.

Our empirical results contribute to a growing body of literature on asymmetric information in insurance markets. While we find that one's assessment of his or her financial condition should the need for nursing care arise is correlated with insurance coverage, future research

\footnotetext{
${ }^{33}$ Cohen and Siegelman (2010).
} 
is needed to understand this relationship more fully. A more complete understanding of this relationship could result in a market less plagued by the deleterious effects of adverse selection and more capable of providing financial security to those at risk of someday needing long-term nursing care.

Significant changes have occurred in the German LTC insurance market since 1992. The results reported in this study shed light on the decisions made by individuals operating in a particular market at a particular time with particular information. Although it is not unreasonable to expect individuals to approach decision-making in today's market with a similar conceptual framework as individuals did in 1992, the significant changes that have occurred in the marketplace since then provide different influences on decision-making than that whichexisted in 1992.

\section{References}

Akerlof, G.A. (1970) 'The market for "lemons": Quality uncertainty and the market mechanism', The Quarterly Journal of Economics 84(3): 488-500.

Barksy, R.B., Juster, F.T., Kimball, M.S. and Shapiro, M.D. (1997) 'Preference parameters and behavioral heterogeneity: An experimental approach in the health and retirement study', The Quarterly Journal of Economics 112(2): 537-579.

Barseghyan, L., Prince, J. and Teitelbaum, J.C. (2011) 'Are risk preferences stable across contexts? Evidence from insurance data', The American Economic Review 101(2): 591-631.

Besche, A. (2003) Die Pflegeversicherung. [Long-term Care Insurance (in German)] Cologne: Bundesanzeiger.

Browne, M.J. (2006) 'Adverse selection in the long-term care insurance market', in P.-A. Chiappori and C. Gollier (eds.) Competitive Failures in Insurance Markets, Cambridge: MIT Press, pp. 97-112.

Bundesaufsichtsamt für das Versicherungswesen (BAV) [German Federal Supervisory Agency for Insurance] (1992) 'Anordnungen und Verwaltungsgrundsätze [Directives and and administrative principles]', Veröffentlichungen des BAV 41(5): 158-160.

Cawley, J. and Philipson, T. (1999) 'An empirical examination of information barriers to trade in insurance', The American Economic Review 89(4): 827-846.

Chiappori, P.-A. (2000) 'Econometric models of insurance under asymmetric information', in G. Dionne (ed.) Handbook of Insurance, Boston, MA: Kluwer Academic Publishers, pp. 365-393.

Chiappori, P.-A. and Salanié, B. (2000) 'Testing for asymmetric information in insurance markets', Journal of Political Economy 108(1): 56-78.

Chiappori, P.-A., Jullien, B., Salanié, B. and Salanié, F. (2006) 'Asymmetric information in insurance: General testable implications', The RAND Journal of Economics 37(4): 783-798.

Cohen, A. and Einav, L. (2007) 'Estimating risk preferences from deductible choice', The American Economic Review 97(3): 745-788.

Cohen, A. and Siegelman, P. (2010) 'Testing for adverse selection in insurance markets', The Journal of Risk and Insurance 77(1): 39-48.

de Meza, D. and Webb, D. (2001) 'Advantageous selection in insurance markets', The RAND Journal of Economics 32(2): 249-262.

Deutsche Aktuarvereinigung (DAV) (2009) 'Herleitung der Rechnungsgrundlagen DAV 2008 P für die Pflegerenten (zusatz)versicherung,' [Derivation of Actuarial Basis DAV 2008 P for Long-Term Care Life Annuities (Complementary Insurance) (in German)]', Blätter der DGVFM 30(1): 31-140.

Department of Health of the United Kingdom (DH) (2004) At Least Five a Week: Evidence on the Impact of Physical Activity and Its Relationship to Health, from http://webarchive.nationalarchives.gov .uk/20130107105354/http://www.dh.gov.uk/prod_consum_dh/groups/dh_digitalassets/@dh/@en/documents/ digitalasset/dh_4080981.pdf, accessed 25 January 2010.

Einav, L., Finkelstein, A., Pascu, J. and Cullen, M.R. (2012) 'How general are risk preferences? Choices under uncertainty in different domains', The American Economic Review 102(6): 2606-2638. 
Fang, H., Keane, M.P. and Silverman, D. (2008) 'Sources of advantageous selection: Evidence from the medigap insurance market', Journal of Political Economy 116(2): 303-350.

Finkelstein, A. and McGarry, K. (2006) 'Multiple dimensions of private information: Evidence from the long-term care insurance market', The American Economic Review 96(4): 938-958.

Geraedts, M., Heller, G.V. and Harrington, C.A. (2000) 'Germany's long-term-care insurance: Putting a social insurance model into practice', The Milbank Quarterly 78(3): 375-401.

Grupp, J., Richter, H. and Wolfsdorf, K. (1992) 'Die Ableitung der neuen Pflegefallwahrscheinlichkeiten für die Pflegerentenversicherung [Derivation of the new long-term care incidence rates for long-term care pension]', Blätter der DGVFM 20(4): 517-534.

Hemenway, D. (1990) 'Propitious selection', The Quarterly Journal of Economics 105(4): 1063-1069.

Koufopoulos, K. (2008) Asymmetric Information, Heterogeneity in Risk Perceptions and Insurance: An Explanation to a Puzzle. World Wide Web: http://ssrn.com/abstract $=1301522$, accessed 25 January 2010.

McCarthy, D. and Mitchell, O.S. (2010) 'International adverse selection in life insurance and annuities', in S. Tuljapurkar, N. Ogawa and A.H. Gauthier (eds.) Ageing in Advanced Industrial States-Riding the Waves Volume 3. International Studies in Population series, vol. 8. Heidelberg: Springer Verlag, pp. 119-138.

Pauly, M.V. (1990) 'The rational nonpurchase of long-term-care insurance', Journal of Political Economy 98(1): 153-168.

Rothschild, M. and Stiglitz, J. (1976) 'Equilibrium in competitive insurance markets: An essay on the economics of imperfect information', The Quarterly Journal of Economics 90(4): 629-649.

Saito, K. (2006) 'Testing for asymmetric information in the automobile insurance market under rate regulation', The Journal of Risk and Insurance 73(2): 335-356.

Sandroni, A. and Squintani, F. (2007) 'Overconfidence, insurance, and paternalism', The American Economic Review 97(5): 1994-2004.

Verband der privaten Krankenversicherung (PKV) [Private Health Insurance Association] (1998) Die private Krankenversicherung - Zahlenbericht 1997/1998 [Private Health Insurance - Data Report 1997/1998], from, https://www.pkv.de/service/zahlen-und-fakten/archiv-pkv-zahlenbericht/zahlenbericht_1997_1998.pdf .

World Health Organization (WHO) (2001) The World Health Report 2001: Mental Health: New Understanding, New Hope, Geneva: WHO.

Zhou-Richter, T., Browne, M.J. and Gründl, H. (2010) 'Don't they care? Or, are they just unaware? Risk perception and the demand for long-term care insurance', The Journal of Risk and Insurance 77(4): 715-747.

Zweifel, P. and Strüwe, W. (1998) 'Long-term care insurance in a two-generation model', The Journal of Risk and Insurance 65(1): 13-32.

\section{About the Authors}

Mark J. Browne holds the Robert Clements Distinguished Chair in Risk Management at St. John's University. He is an Associate Member of the Munich Risk and Insurance Center at the Ludwig Maximilians Universitat in Munich, Germany, and is a member of the International Research Advisory Board of the Risk and Insurance Research Center at National Chengchi University in Taipei, Taiwan. Dr Browne has served as president of the American Risk and Insurance Association (ARIA) and the Risk Theory Society.

Tian Zhou-Richter is a corporate actuary at Munich Health, the healthcare segment within Munich Reinsurance Company. She holds a PhD in Business Administration from the Humboldt University of Berlin, Germany. 